\title{
Tracking Invasive Alien Species (TrIAS): Building a data-driven framework to inform policy
}

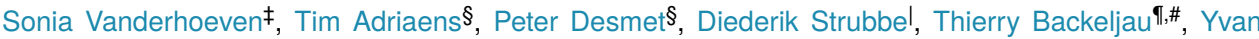 \\ Barbier $^{a}$, Dimitri Brosens§,", Julien Cigar", Maxime Coupremanne ${ }^{\ddagger}$, Rozemien De Troch”, Hilde \\ Eggermont“`, André Heughebaert“, Kris Hostens`, Pierre Huybrechts“, Anne-Laure Jacquemart”, Luc \\ Lens', Arnaud Monty', Jean-Yves Paquet ${ }^{3}$, Céline Prévot', Tim Robertson ${ }^{\$}$, Piet Termonia",, , Ruben \\ Van De Kerchove ${ }^{-\beta}$, Gert Van Hoey ${ }^{P}$, Bert Van Schaeybroeck", Diemer Vercayie ${ }^{A}$, Thomas Jethro \\ Verleye $^{z}$, Sarah Welby ${ }^{\mathrm{F}}$, Quentin John Groom ${ }^{\mp}$ \\ $\ddagger$ Belgian Biodiversity Platform, Gembloux, Belgium \\ $\S$ Research Institute for Nature and Forest (INBO), Brussels, Belgium \\ | Terrestrial Ecology Unit, Ghent University, Ghent, Belgium \\ If Royal Belgian Institute of Natural Sciences, Brussels, Belgium \\ \# University of Antwerp, Antwerp , Belgium \\ a Département d'étude du milieu naturel et agricole, Service Public de Wallonie, Gembloux, Belgium \\ «Belgian Biodiversity Platform, Brussels, Belgium \\ "Royal Meteorological Institute of Belgium, Brussels, Belgium \\ ^ Institute for agricultural and fisheries research (ILVO), Merelbeke, Belgium \\ v Université catholique de Louvain, Louvain-la-Neuve, Belgium \\ Biodiversity and Landscape, Gembloux Agro-Bio Tech, University of Liege, Gembloux, Belgium \\ $?$ Natagora, Liège, Belgium \\ ` Département d'étude du milieu naturel et agricole, Gembloux, Belgium \\ ¿ Global Biodiversity Information Facility, Copenhagen, Denmark \\ \& Ghent University, Ghent, Belgium \\ \& Flemish institute for technological research (VITO), Mol, Belgium \\ P Institute for Agricultural and Fisheries Research (ILVO), Oostende, Belgium \\ A Natuurpunt Studie vzw, Mechelen, Belgium \\ z Flanders Marine Institute (VLIZ), Ostend, Belgium \\ F CODA-CERVA, Uccle, Belgium \\ ₹ Botanic Garden Meise, Meise, Belgium
}

Corresponding author: Sonia Vanderhoeven (s.vanderhoeven@biodiversity.be), Quentin John Groom (qgroom@ botanicalkeys.co.uk)

Received: 25 Apr 2017 | Published: 02 May 2017

Citation: Vanderhoeven S, Adriaens T, Desmet P, Strubbe D, Backeljau T, Barbier Y, Brosens D, Cigar J, Coupremanne M, De Troch R, Eggermont H, Heughebaert A, Hostens K, Huybrechts P, Jacquemart A, Lens L, Monty A, Paquet J, Prévot C, Robertson T, Termonia P, Van De Kerchove R, Van Hoey G, Van Schaeybroeck B, Vercayie D, Verleye T, Welby S, Groom Q (2017) Tracking Invasive Alien Species (TrIAS): Building a data-driven framework to inform policy. Research Ideas and Outcomes 3: e13414. https://doi.org/10.3897/rio.3.e13414 


\section{Abstract}

Imagine a future where dynamically, from year to year, we can track the progression of alien species (AS), identify emerging problem species, assess their current and future risk and timely inform policy in a seamless data-driven workflow. One that is built on open science and open data infrastructures. By using international biodiversity standards and facilities, we would ensure interoperability, repeatability and sustainability. This would make the process adaptable to future requirements in an evolving AS policy landscape both locally and internationally. In recent years, Belgium has developed decision support tools to inform invasive alien species (IAS) policy, including information systems, early warning initiatives and risk assessment protocols. However, the current workflows from biodiversity observations to IAS science and policy are slow, not easily repeatable, and their scope is often taxonomically, spatially and temporally limited. This is mainly caused by the diversity of actors involved and the closed, fragmented nature of the sources of these biodiversity data, which leads to considerable knowledge gaps for IAS research and policy. We will leverage expertise and knowledge from nine former and current BELSPO projects and initiatives: Alien Alert, Invaxen, Diars, INPLANBEL, Alien Impact, Ensis, CORDEX.be, Speedy and the Belgian Biodiversity Platform. The project will be built on two components: 1) The establishment of a data mobilization framework for AS data from diverse data sources and 2) the development of data-driven procedures for risk evaluation based on risk modelling, risk mapping and risk assessment. We will use facilities from the Global Biodiversity Information Facility (GBIF), standards from the Biodiversity Information Standards organization (TDWG) and expertise from Lifewatch to create and facilitate a systematic workflow. Alien species data will be gathered from a large set of regional, national and international initiatives, including citizen science with a wide taxonomic scope from marine, terrestrial and freshwater environments. Observation data will be funnelled in repeatable ways to GBIF. In parallel, a Belgian checklist of AS will be established, benefiting from various taxonomic and project-based checklists foreseen for GBIF publication. The combination of the observation data and the checklist will feed indicators for the identification of emerging species; their level of invasion in Belgium; changes in their invasion status and the identification of areas and species of concern that could be impacted upon by bioinvasions. Data-driven risk evaluation of identified emerging species will be supported by niche and climate modelling and consequent risk mapping using critical climatic variables for the current and projected future climate periods at high resolution. The resulting risk maps will complement risk assessments performed with the recently developed Harmonia+ protocol to assess risks posed by emergent species to biodiversity and human, plant, and animal health. The use of open data will ensure that interested stakeholders in Belgium and abroad can make use of the information we generate. The open science ensures everyone is free to adopt and adapt the workflow for different scenarios and regions. The checklist will be used at national level, but will also serve as the Belgian reference for international databases (IUCN - GRIIS, EASIN) and impact assessments (IPBES, SEBI). The workflow will be showcased through GEO BON, the Invasivesnet network and the COST Actions Alien Challenge and ParrotNet. The observations and outcomes of risk evaluations will be used to provide science-based 
support for the implementation of IAS policies at the regional, federal and EU levels. The publication of Belgian data and checklists on IAS is particularly timely in light of the currently ongoing EU IAS Regulation and its implementation in Belgium. By proving that automated workflows can provide rapid and repeatable production of information, we will open up this technology for other conservation assessments.

\section{Keywords}

Information Technology; Risk Evaluation; Evidence-Based Policy; Open Data Publication; Climate Change

\section{State of the Art and Objectives}

Biogeography, dispersal biology and pest control were formerly a static study of defined distributions, local dispersal, and well-defined sets of organisms. However, globalization has forced us to think from a dynamic, long-term perspective for a whole suite of organisms, particularly with regard to AS. Human-mediated introductions of AS have become a defining feature of global environmental change (Tittensor et al. 2014; van Kleunen et al. 2015). The rate of increase of IAS that pose a threat to biodiversity and ecosystem services confronts managers, policy makers and researchers, who have to deal with information that is rapidly out-of-date. Access to recent, accurate and reliable IAS distribution data are key to addressing the problems these invaders pose. Reducing barriers to data sharing will significantly improve our ability to react as quickly as possible to the challenge of biological invasions (Groom et al. 2015). A sound scientific basis is needed to guide decision-makers on how to minimize the risk and impacts of invasive species (McGeoch et al. 2012; Roy et al. 2014). We not only need to deal with the issues of IAS today, we also need to predict their impact in the future and design policies that are proactive, adaptable and proportionate, taking into account climate change and other anthropogenic environmental change likely to affect IAS range dynamics and impacts. Recent legislative initiatives, such as the EU Regulation 1143/2014 on IAS lend substantial impetus for Member States to deliver information on AS, resulting in an important challenge with regard to the range, quality and scope of information sources, supporting tools, data infrastructure and information systems (Latombe et al. 2016). In recent years there has been global progress towards improving the collection, management and delivery of biodiversity observations both for the scientific community and for policy makers. At the forefront of this has been GBIF, a global infrastructure providing data publishing services to data providers and equipping scientists with tools to examine these data. Alien species registries, exhaustive documented lists of AS present in a territory, are important tools to address the selection of species for risk assessment and derived lists of IAS have formed the basis of many policy initiatives (Lodge et al. 2006, McGeoch et al. 2012, Roy et al. 2014, Latombe et al. 2016). Alien species occurrence, spatially explicit presence-absence, is equally relevant to multiple risk-related research activities such as niche and occupancy modelling, climate matching and change monitoring. Easy access to these types of data 
and fast dissemination are indispensable. Information derived from these data should ideally feed into the risk evaluation process for AS and therefore form a sound scientific basis to guide decision making. Transparent use of available data in risk assessment and decision making is crucial to guarantee reliability, credibility and endorsement of the outcomes by stakeholders and the public (Hattingh 2011, McGeoch et al. 2012) and to ensure efficient allocation of available biodiversity conservation budget. In recent years, Belgium has developed valuable decision support tools to inform IAS policy, including information systems, early warning initiatives (waarnemingen.be, observations.be) and risk assessment protocols (Vanderhoeven et al. 2015, D'hondt et al. 2015). The BBPF, as Belgian node of GBIF (BeBIF), has supported data publication and provided tools to allow policy decisions to be taken on IAS. However, such systems only become optimal if they are supported with up-to-date and accurate data at appropriate spatial scales. Yet, currently, workflows from biodiversity observations to IAS science and policy are slow, not easily repeatable and their scope is often taxonomically, spatially and temporally limited. This is mainly caused by the diversity of actors involved and the closed, fragmented nature of the sources of these biodiversity data. Despite the obvious advantages of fast and open data availability, IAS science struggles to meet the current growing demand for IAS data. Imagine a situation where dynamically, we can track the progression of AS, identify emerging species, assess their current and future risk, and timely inform policy using a seamless data-driven workflow. One that is built on open science and open data infrastructures. By using international biodiversity standards and facilities, we would ensure interoperability, repeatability, and sustainability. This would make the process adaptable to future requirements in an evolving IAS policy landscape both locally and internationally. The Belgian Science Policy Office (BELSPO) has financed several projects focusing, fully or partly, on IAS and their current and foreseen impacts and risks. We will leverage expertise and knowledge from nine former and current BELSPO projects and initiatives Alien Alert, Invaxen, Diars, Inplanbel, Alien Impact, Ensis, CORDEX.be, Speedy and the Belgian Biodiversity Platform - to develop a data-driven framework to inform IAS policy. This framework will will be built on two components:

1. The establishment of a data mobilization framework for AS data from diverse data sources;

2. The development of data-driven procedures for risk evaluation based on risk modelling, risk mapping and risk assessment.

\section{Methods}

Alien species checklist : Species' alien status, and a priori knowledge of the presence of an alien species in a country, is central to target monitoring and control strategies (Latombe et al. 2016). Assigning alien status to a species is not always straightforward and may be subjected to different types of errors such as misidentification and taxonomic uncertainty (McGeoch et al. 2012). The TrlAS partnership brings together the owners of various databases considered to be authoritative sources in Belgium, such as the Manual of Alien Plants of Belgium (Verloove 2016) and the VLIZ Alien Species List for the Belgian part of 
the North Sea and the Scheldt Estuary (Vandepitte et al. 2012). This will allow us to build an aggregated, reproducible checklist of alien species occurring in Belgium. For each species, the checklist will include policy-relevant attributes such as pathways of introduction, habitats and native range. To allow for fast inclusion of new and updated information, TrlAS will facilitate the (re)publishing of checklists by owners of the authoritative sources. These will be open, machine-readable datasets using standardized terminology and the GBIF infrastructure will be used to aggregate these automatically into a single, derived checklist. The resulting Belgian Alien Species checklist will be used to validate and/or update the information for Belgium included in several global databases, such as DAISIE, EASIN, WRIMS and GRIIS.

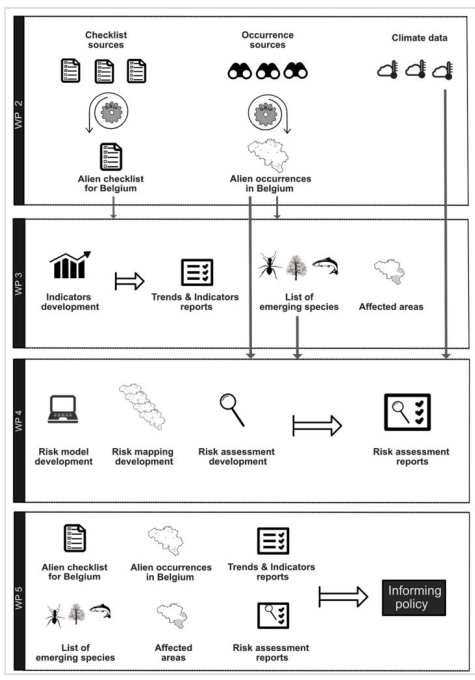

Figure 1.

A visual description of the TrlAS workflow through work packages. Work package 1 generates the input data; Work package 2 creates indicators and summaries of the data; Work package 3 uses the data and generates models and predications of future distributions; Work package 4 involves experts using the information from the other work packages, together with their own experience to create impact assessments.

Alien species occurrence data : Spatially and temporally explicit species occurrence records are the basic unit to track and assess range expansion of species (McGeoch and Latombe 2015). Quantifying the extent and nature of invasions requires harmonized occurrence data across the area of interest, promptly collated on a regular basis. As with the AS checklist, TrIAS will facilitate owners of important sources of AS occurrence records for Belgium, including major citizen science initiatives, to publish these as open, machinereadable datasets to GBIF. As the structure of this data is highly heterogeneous, these will be standardized to allow integration. This will significantly increase the quantity and quality of available AS occurrence data for Belgium. The GBIF infrastructure and AS checklist will be used to filter the occurrence data on the species of interest to create a single AS species occurrence dataset for Belgium in a repeatable way. 
Climate data and scenario : Several databases offer free access to a wide range of global bioclimatic variables, such as WorldClim (Hijmans et al. 2005) and CliMond (Kriticos et al. 2011). Such climatological datasets are essential to model species distributions under current and future climates based on species climatic niches (Broennimann et al. 2007; Di Febbraro et al. 2013). However, the climate-change data in such global datasets are based on the low resolution CMIP5 standard model predictions (http://cmip-pcmdi.IInl.gov/cmip5/). Although they are suitable for large-scale studies focussing on species range dynamics at global and continental scales, they fail (i) to properly cover the Belgian territory, as Belgium is represented by only a few grid cells and (ii) to consider climate extremes, including heat waves, droughts, strong wind gusts or heavy precipitation. High resolution climatic data are needed for robust and reliable modelling of climatic suitability for invading species, as AS may respond more strongly to climatic extremes rather than averages (Easterling 2000). Regional climate downscaling (RCD) can provide projections with much greater detail and more accurate representation of localised extreme events. TrIAS will provide highresolution data and maps for the current climate as well as for projected climate change scenarios in Belgium, including related uncertainty estimates. These will be used as a core input for risk modelling, risk mapping and consequent risk evaluation of $A S$ in Belgium under current and future climatic conditions.

\section{Trends and indicators}

Aichi Target 9 of the 2011-2020 Strategic Plan for Biodiversity states that "By 2020, IAS should be identified and prioritized, priority species controlled or eradicated and measures should be in place to manage invasion pathways" (CBD Secretariat 2010) and target 5 of the European stratagy for Biodiversity has a similar aim (European Commission 2011). To follow up on the progress towards policy goals, a number of indicators were developed at international level (Rabitsch et al. 2012; Rabitsch et al. 2016). In Belgium, some AS indicators are in use on a regional level (Demolder et al. 2015), though they are lacking at the national level. The regular process of feeding these indicators with data is ad-hoc and the quality depends on updating efforts. This reduces their reliability, which ideally should meet internationally established quality standards (Layke et al. 2012). Full spatial coverage is required, and processes should constitute part of a sustainable monitoring system (European Environment Agency 2012). TrIAS will review existing AS indicators, especially with regards to internationally agreed standards (e.g. Biała et al. 2012), the Essential Biodiversity Monitoring Variables (EBVs) framework (McGeoch and Latombe 2015) and temporal sensitivity (Latombe et al. 2016). The selected indicators will be applied to the TrIAS checklist and occurrence data to 1) report on the evolution of biological invasions in Belgium; 2) identify species and areas of concern and 3) select emerging species triggering further risk evaluation. Where possible, indicators will be calculated for the current year and retroactively so that we can already develop a baseline and signal underlying trends. 


\section{Data-driven procedures for risk evaluation}

Proper decisions for IAS management depend on accurate spatial and temporal characterization of the evaluation of entry, exposure and consequence (Venette et al. 2010). As such, data-driven risk evaluation should provide timely insight about the potential range and impact of an AS. In recent years, Belgium has drafted comprehensive risk assessments for a number of species (Vanderhoeven et al. 2015). However, these documents mostly represent single-expert assessments and for some aspects, such as establishment potential, exposure and occurrence in natural areas, they are often based on expert opinion rather than on empirical data (Vanderhoeven et al. in press). TrlAS will build on the experience acquired from the Alien Alert project and its Harmonia+ protocol (D'hondt et al. 2014,D'hondt et al. 2015) to develop a data-driven risk evaluation process founded on risk modelling, risk mapping and risk assessment, taking into account different future climatic scenarios. This process will be applied to emerging species identified from the trends and indicators.

Risk modelling and mapping : Spatially explicit predictions of invasion risk derived from species distribution models [SDMs, also known as ecological niche models (ENMs)], calibrated with native species distributions, are increasingly incorporated into alien species risk assessments (Beaumont et al. 2014). SDMs/ENMs are statistical techniques that relate species occurrence data to spatial environmental predictors. These models estimate the geographical distribution of climates and habitats suitable for a species (Araújo and Peterson 2012). In order to provide robust estimates of species' invasion potential and the uncertainties inherently associated with such predictions, TrIAS will apply a dynamic, multistep modelling framework. For emerging species identified through the developed framework, spatially explicit forecasts of environmental suitability (termed 'invasion risk') based on the species' current distribution elsewhere (the 'global' model) will be generated. Second, Belgian occurrence data and fine-grained information on climate and habitats will be made available in the project and used to refine global model predictions of invasion risk (Gallien et al. 2012). As SDM/ENM techniques are inherently correlative, they in fact model only species' realized, not fundamental niches, risking an underprediction of areas at risk of invasion. Therefore, in order to characterize species niches as adequately as possible, following Broennimann and Guisan (2008), we will evaluate three occurrence data selection strategies for the global invasion risk model, namely native-range occurrences only, native-range plus Belgian occurrences, and native-range plus alien occurrences worldwide. As there is continuing debate on the relative accuracy of the different modelling algorithms, invasion risk predictions will be obtained using an ensemble-modelling technique. Ensemble models reduce inter-algorithm variability by integrating the predictions of a large set of modelling methods and input settings (Araujo and New 2007). Model predictions will be dynamically generated for both current and future climate conditions at 30-year intervals (see data description). The modelling framework will be coded in open source, annotated R-code, allowing the models to be re-run and updated when new distribution data become available. The modelling framework moves beyond the state-ofthe-art in several respects. First, while validation of distribution model predictions using independent data (i.e. data not used in model building) is a necessary prerequisite for 
assessing model robustness and reliability (Guisan and Zimmermann 2000), such data are often not available. The proposed framework does allow for this, as models calibrated using native-range occurrence data will be evaluated against species' known, current invasive distributions before generating forecasts of invasion potential. Second, the use of different data selection strategies for characterizing species' niches combined with an ensemble modelling approach allows quantification of the uncertainties associated with species' potential distributions under current and future climates, rather than trying to identify a single 'best' model (Buisson et al. 2010). Lastly, in contrast to the static way in which SDM-based invasion risk predictions are commonly presented, the proposed modelling framework flexibly allows updating of the models when new species occurrence data become available (Franklin 2010, Václavík and Meentemeyer 2011).

Risk assessment : Risk assessment protocols are tools to condense species information into their perceived risks according to a common framework. The Belgian Harmonia+ risk assessment protocol was designed during the BELSPO project Alien Alert (D'hondt et al. 2014, D'hondt et al. 2015). Harmonia+ represents a first-line risk assessment scheme for potentially invasive organisms that may raise concerns for environmental, plant, animal and human health. Pandora+ is a complementary version of Harmonia+, suitable for pathogenic and parasitic (micro)organisms, the results of which may feed into Harmonia+ (Roelandt et al. 2017). The protocol was designed to be used in a documented, guided expert elicitation process and has recently been implemented online in a repeatable, documented workflow, created by the Belgian Biodiversity Platform (http://ias.biodiversity.be/harmoniaplus). The results of the risk modelling and mapping will be implemented into Harmonia+ as supporting tools for experts to assess species' establishment capacity, potential impact and the influence of climate change. Primarily designed for freshwater and terrestrial species, Harmonia+ will be adapted during TrlAS for marine species. Risk assessments will be carried out on identified emerging species in a moderated participatory process, including different rounds of consensus building (Mukherjee et al. 2015). Furthermore, risk assessments will be updated as and when new information becomes available in order to further integrate identified emerging species into the listing scheme (watch, grey and black lists) of AS in Belgium.

\section{Informing policy}

A critical, yet often overlooked, area of risk analysis is the dissemination of information on the risks of AS introductions through risk communication. Ensuring repeatability, reliability, and transparency in both the data mobilization framework and the risk evaluation process will effectively increase understanding of the risks encountered and therefore facilitate the decision making (Venette 2015). TrIAS will pay particular attention to two challenging issues: the consideration of uncertainty and knowledge transfer. Yet, for many species, especially those that are emerging problems, risk assessments are hampered by a lack of evidence on species' impacts, conflicting evidence and context dependent variability, hindering optimal management actions (Vanderhoeven et al. in press). Uncertainty however is intrinsically associated with risk and disregarding it may lead to suboptimal decisions. Innovative solutions will be explored to clearly visualize risk and related 
uncertainty (Holt et al. 2012). Knowledge transfer will consequently include careful translation of TrIAS results to plain language that does not depend on mathematical expressions. To achieve this, TrIAS will rely on the experience of the Belgian Forum on Invasive Species and target the appropriate audience through its information system Harmonia.

\section{Data}

TrIAS will make use of existing species occurrence data (mostly observations, but also specimens) from regional administrations (INBO, ILVO \& SPW-DEMNA), NGOs (Natuurpunt \& Natagora), collections (BGM, RBINS), former AS related projects (Invaxen, Diars, Inplanbel, Ensis, MEMO), and AS data available on GBIF. Dedicated monitoring for AS is currently lacking in Belgium. Yet, several monitoring schemes, such as for Natura 2000, the Water Framework Directive and the Marine Strategy Framework Directive yield data on AS. Also, there are many opportunistic observations by citizen scientists. These data have never been brought together, but together they would represent the most complete and up to date source of AS occurrence data for Belgium. Where not the case already, these data will be standardized and published as open data through GBIF, so these can be used for data-driven procedures in TrIAS as well as by anyone else. In order to specifically select AS occurrence data, a verified and standardized list of all AS in Belgium is required. As such a unified checklist does currently not exist, TrlAS will make use of several authoritative checklists with a more specialized scope that collectively comprise the most complete data source for AS in Belgium. These include the Manual of Alien Plants (BGM, Verloove 2006, Verloove 2016), the Harmonia information system (BBPF, Vanderhoeven et al. 2015), the World Register of Introduced Marine Species (WRIMS) (VLIZ, Pagad et al. 2016), the Registry of non-native species in the Two Seas region countries (Great Britain, France, Belgium and the Netherlands) (RINSE) (INBO,Gallardo et al. 2013, Zieritz et al. 2014, Gallardo et al. 2015), non-indigenous freshwater fish (INBO, Verreycken et al. 2007), alien freshwater invertebrates (UGent, Boets et al. 2016), and terrestrial Mollusca (RBINS, from EASIN Katsanevakis et al. 2015). TrIAS will also explore the possibility to fill potential taxonomic gaps by publishing non-ASoriented checklists, containing both native and AS data, such as Bryophytes (Sotiaux and Vanderpoorten 2001), lichens (Ertz et al. 2008), rust fungi (Vanderweyen and Fraiture 2007), and smut fungi (Vanderweyen and Fraiture 2014). Climate conditions used for risk modelling and mapping will be based on multiple datasets. Global species distribution model (current and future) climate input data will be gathered from generic online databases such as the above-mentioned WorldClim and CliMond repositories, as well as from the international EURO-CORDEX project. Belgian-level current and future climate data will be derived from the Belgian CORDEX.be project, which is a BELSPO-funded project through which, at the beginning of 2017, state-of-the-art regional climate models (i.e. MAR, ALARO, COSMO-CLM) with a spatial resolution about $4 \mathrm{~km}\left(\sim 16 \mathrm{~km}^{2}\right)$ will be available. To derive relevant climate change signals, both data from the past and different future greenhouse gas scenarios will be considered. Belgian-level habitat and land-use 
data will be collated from TrIAS partners and harmonized across the country before use as predictor variable for invasion risk models (see below).

\section{Workplan and detailed description of tasks}

\section{Work Package 1 - Management}

The coordinator will be responsible for the overall management of the project and the generation of the deliverables. The lead scientist in each institution will be responsible for their day-to-day task management. A formal meeting of the whole consortium will be held every six months, whereas ad hoc meetings of the task groups will be called by the task leaders or coordinator as it is deemed necessary. The whole team will work with the followup committee. Three meetings of the follow-up committee with the complete consortium are envisaged, one in month 1 of the project, one midway through the project and one during the final three months. The follow up committee meetings will be held at the same time as meetings of the whole consortium to reduce costs and optimise attendance. These meetings will serve to direct and consolidate the project, address problems, and get feedback from the follow-up committee. In addition, teleconference meetings and email will be used extensively to ensure coordinated working across the partners. The management will ensure progress of deliverables and milestones will be closely monitored to ensure that deadlines are met.

\section{Task 1.1: Data Management Plan}

The data management plan will describe how the information generated by the project will be handled both during and after it is generated, and will be designed to ensure that data are of good quality, standardized for better reusability, assigned appropriate metadata, and are adequately preserved (McLure et al. 2014). The TrIAS project data management plan will be delivered at the end of month 2 . This plan will contain detail of the open data philosophy of the project which relates to roles and responsibilities for data. This plan will make it clear to partners and other interested stakeholders how the project handles issues related to the preservation, sharing and organization of data. This will include important issues such as citation, data sharing; embargoing data and sensitive data. Specific issues that will be addressed include how research data, software and results are handled after the end of the project; it will detail the formats, standards and minimum requirements that will be used during the project. Furthermore, it will detail those responsible for ensuring this happens. The overall aim will be to support scientific reproducibility and reliability of the project's results, both during the project and in the long term.

\section{Task 1.2: Follow-up Committee Reports}

Before the second and third follow-up committee meetings a status report will be written detailing the progress of the project. This will document the use of resources and the progress towards goals. This report will also be used to report on issues related to gender 
and ethic within the project. Each partner will contribute to this report. They will detail their use of the budget and their individual progress towards aims. If problems are encountered during the project they will be detailed in the report together with the solutions. The report will be used to communicate progress to the follow up committee and to Belspo, but it also a useful milestone for the project to reflect on its progress.

\section{Work Package 2: Data Mobilization Framework}

The goal of the data mobilization framework is to create data products that will be used in further work packages. This includes datasets relating to the presence of AS in Belgium (checklist and occurrence data) for which major sources in Belgium will be published to GBIF, and environmental predictors needed for spatially explicit risk modelling and mapping (global and CORDEX-derived climate (change) data, habitat and land-use layers). The framework also comprises the tools and documentation to compile from the published checklists a unified AS checklist for Belgium, use this to query and download occurrence data from GBIF, and process these to feed further analysis (WP3 \& WP4).

\section{TASK 2.1 - Alien species checklist}

TrIAS will work with the authors of 7 authoritative checklists of AS in Belgium (see "Data") to publish these as standardized, open datasets. Some of these checklists are one-off publications whereas others are dynamic, being continually updated. For each source, we will create a mapping scheme to standardize the original data model to the Darwin Core (DwC) standard, in large part following the GBIF Global Names Architecture (GNA) profile (GBIF 2010). As part of this data mapping process, we will identify missing terms and vocabularies and propose change requests for DwC to the Biodiversity Information Standards (TDWG) community. The checklist data will include species names, vernacular names, sources, and policy-relevant attributes such as pathways of introduction, habitats and native range. Each checklist will be documented with metadata, including contact information, taxonomic and geographic scope, and the open licence under which it is published. Data and metadata will then be packaged as a Darwin Core Archive and registered with GBIF, where it can be indexed and assigned a DOI, allowing the list to be referenced as a versioned, online source. We will use the GBIF Integrated Publishing Toolkit (IPT) (Robertson et al. 2014) to setup this publication process for each source, empowering the authors to periodically re-publish their dataset easily when new and updated information becomes available. For dynamic checklists, re-publication will be done at least once in the course of the project. In a next step, we will retrieve these checklist data through the GBIF species Application Programming Interface (API). The advantage of doing so is that the species names will be linked to the GBIF backbone taxonomy (GBIF Secretariat 2016), which provides a unified classification, and that we can retrieve all relevant data through a single, repeatable protocol. Experts of the Belgian Forum on Invasive Species will verify species names identified as synonyms, map values deviating from controlled vocabularies to a standard value, and define a decision tree when checklists diverge. After this, all information will be aggregated on accepted species 
names, creating a unified AS checklist for Belgium. This dataset will be versioned and published on GBIF, so it can be used and referenced easily. This unified AS checklist will replace the existing Invasive Alien Species in Belgium - HARMONIA database checklist. The workflow to create this checklist will be developed and documented as an open source protocol on GitHub, an online code collaboration platform allowing anyone to explore and understand how it works. The unified checklist will be updated whenever a source dataset is updated or added. We will contract GBIF to implement missing query possibilities or data attributes in the APIs we use, as well as to improve the build procedure of the GBIF backbone taxonomy.

\section{TASK 2.2 - Occurrences}

As with the AS checklist, TrlAS will work with the owners of important sources of AS occurrence records for Belgium (see "Data") to publish these as standardized, open datasets. For each source, we will create a mapping schema to standardize the original data model to the Darwin Core (DwC) standard. The published occurrence data will at least include the species name, date, location and source information for each record. As with the checklists, each dataset will be documented with metadata and will be packaged as a Darwin Core Archive and registered with a DOI. We will use the GBIF Integrated Publishing Toolkit (IPT) (Robertson et al. 2014) of the Belgian Biodiversity Platform to setup this publication process for each source, empowering the owners - especially those of dynamic occurrence sources (such as Natuurpunt \& Natagora) - to periodically re-publish their dataset easily when new or updated information becomes available. For dynamic occurrence sources, republication will be done at least once in the course of the project. The IPT also allows the owners to publish other non-AS-oriented occurrence sources they might hold. In a next step, we will query and download these and other occurrence data through the GBIF occurrence and download API. As filters we will use the unified AS checklist to target species of interest and relevant data quality flags. Using the GBIF infrastructure to do so offers several advantages: it provides a single, repeatable protocol to retrieve all relevant data, it not only targets the occurrence data published through TrIAS, but all relevant AS data for Belgium, it queries for accepted species names and all their related synonyms, and it creates a citable data package with a DOI for each download. We will develop and use a number of automatic data quality assessments to process and clean the data. This way, TrIAS will produce a single, reproducible AS occurrence dataset for Belgium directly usable in further work packages. We will contract GBIF to implement or optimize missing query possibilities or data attributes in the APIs we use.

\section{TASK 2.3 - Climatic Data and Future Scenarios}

The aim of this task is to develop climate prediction products targeted for enabling risk modelling (WP4) and consequent risk assessment (WP3.3) for Belgium under current and future climate conditions. While climate data needed for the 'global' species distribution models can be easily derived from online repositories, fine-grained Belgian-level models require tailored high-resolution data and GIS layers for current and future climates. In TriAS, such datasets will be prepared, based on and adapted from the high-resolution 
$\left(4 \mathrm{~km}, 16 \mathrm{~km}^{2}\right)$ results of the BELSPO-funded CORDEX.be project. These Belgian-level climate predictions will be obtained using multiple dynamically-downscaled simulations, and will explicitly include climate uncertainty estimates. Such high resolution data are required for different reasons, including a realistic representation of convective rain (De Troch et al. 2013). Taxon-specific default sets of predictor variables will be selected (see below, WP4), and for each selected climate variable, the most relevant spatial extent and temporal resolution (daily, monthly, yearly) will be defined. Different time periods will be considered: (a) the historical period (1980-2010) and (b) three future climate periods (2010-2040, 2040-2070 and 2070-2100), all for three greenhouse gas scenarios (Representative Concentration Pathways 2.6, 4.5 \& 8.5). Additionally, for the second option (b) the climate changes with relation to the current-day climate will be explored. The uncertainty associated with these climate predictions across Belgium will be estimated taking into account the findings from the international EURO-CORDEX ensemble (Giot et al. 2016, Prein et al. 2015). Climate simulations are known to suffer from model biases (Kotlarski et al. 2014) and misrepresented climate change trends (van Oldenborgh et al. 2013). Corrections and care in interpretation of the data are therefore required. In that context the expertise gained during the CORDEX.be project concerning statistical downscaling, bias correction and uncertainty estimation will be essential. Thus, the main output of this task will be, for each climate variable deemed relevant for a given taxon, a set of spatially explicit current and future climate GIS layers that will serve as predictor variables for risk modelling and consequent risk assessments.

\section{WP3 - Trends and Indicators}

Tracking the spread of AS and evaluating the effectiveness of policies and management interventions is generally achieved by repeated measurement of occurrence records of AS. It implies the assessment of their geographic distribution (Latombe et al. 2016). This can be performed by calculating indices for the extent of occurrence and/or the area of occupancy (e.g. Gaston 1991) of an invader based on distribution records. Such procedures can be refined taking into account the type and amount of data, recording effort and recorder bias. The aim of this work package is to develop indicators suited to report on the evolution of biological invasions in Belgium, to define their spatial and temporal sensitivity (the inherent responsiveness of the variable to change which relates to the timescale at which the variable should be reassessed), to explore the feasibility of feeding these indicators into GBIF, based on automated procedures and AS occurrences, and to develop the tools to tackle this in an open-science approach.

\section{TASK 3.1 - Review of existing IAS indicators}

As a first step, TriAS will review existing IAS indicators in Belgium (e.g. Demolder et al. 2015, www.natuurindicatoren.be), such as the cumulative number of alien plant and animal species or the percentage of alien plants in the local flora. We will review these with regards to their relevance to (1) the headline indicators of the CBD Aichi Target 9 on the identification and prioritization of AS and their pathways, (2) their usefulness for long-term 
monitoring of biological invasions in Belgium, (3) internationally agreed standards for invasive species indicators such as the Streamlining European Biodiversity Indicators (SEBI) initiative which has developed a set of indicators for invasive species prevalence at EU level (Rabitsch et al. 2016) including the cumulative number of AS established in terrestrial/marine/estuarine/freshwater environments and the number of the listed 'worst' (i.e. a list of high impact AS) terrestrial and freshwater IAS threatening biodiversity in European countries, and (4) the essential variables for invasion monitoring (McGeoch and Squires 2015) that fit within the broader framework of Essential Biodiversity Variables (EBVs; Pereira et al. 2013).

\section{TASK 3.2 - Development of indicators for biological invasions in Belgium}

Once the relevant indicators for invasion have been defined, TrIAS will develop threshold values for each, allowing us to detect important changes in the trends of the selected indicators. Although IAS indicators at the international level (e.g. trends in the number of IAS and the number of high impact AS) are indispensable, they are not refined enough to provide the necessary information for IAS policy and invasion management at national or regional level (e.g. early warning, risk evaluation and rapid response mechanisms). Also, at national and regional levels, information is needed focussing on certain taxa (e.g. the species of EU concern) or certain areas such as protected areas (e.g. NATURA 2000 areas, nature reserves) and entry points. The same is true for the essential variables for invasion (e.g. alien status) which primarily serve the detection of international/global trends. TrIAS will therefore also consider supplementary information such as abundance of a species, characteristics of the invaded area, pathways of introduction, and spread. We will then develop an open source tool to automatically follow trends in the defined indicators for AS in Belgium, based on public occurrence records registered with GBIF. The tool will allow for processing the occurrence data gathered in WP2, correct these for several biases and combine these with other layers of information pertinent to the indicators we want to follow, such as geospatial layers with habitat or protected area information. We will contract GBIF to assist in the development of this tool, which will potentially be built on the speciespopulation tool developed by them (https://demo.gbif.org/tools/species-population).

\section{TASK 3.3 - Trends and indicators report - identification of emerging alien species and affected areas}

The tools developed in the previous section will be processed with occurrence data gathered in WP2. This will occur twice during the project and will report for which indicators, species and locations certain thresholds have been crossed. The indicators and threshold values defined within TrIAS will act as warnings of important changes in the status of biological invasions in Belgium, such as a change in the number of AS in Belgium, a rate of change in the distribution and/or spread of AS in Belgium, a rate of change in the distribution and/or spread of an AS in protected/priority areas of conservation concern in Belgium (McGeoch and Latombe 2015). This will allow us to infer emerging AS for risk evaluation (WP4) as well as areas affected by biological invasions by these species. 


\section{Work Package 4 - Risk evaluation}

\section{TASK 4.1 - Risk model development}

\section{Data gathering and organization}

Species occurrence data: a first step in risk model development is the collection and organization of required species occurrence data. The data mobilization framework (WP2) will allow us to identify the species for which invasion risk predictions need to be generated. For the global model (i.e. the model aimed at characterizing the full range of climatic conditions under which a species can persist), global species occurrence data will be gathered from various online repositories (including those published by TrIAS). Both generic (e.g. GBIF, OBIS) and taxa-specific repositories (e.g. VertNet, AntNet,..) will be queried. Species occurrence data gathering (and dynamic updating) will be facilitated through the use of designated $\mathrm{R}$ packages that directly communicate with these databases (e.g. the 'rgbif' (Chamberlain et al. 2016) and 'spocc' packages of the rOpenSci project (Chamberlain et al. 2016b)). Even though the data sources mentioned above have standardized quality control procedures before publishing data, multidimensional quality control remains imperative before applying distribution models to data (Beck et al. 2014). To that end, the R package 'speciesgeocodeR' will be applied (Töpel et al. 2016) to downloaded data as this methodology allows for rapid and automatic sorting and cleaning of occurrence data, evaluating geographic and taxonomic data reliability as well as easy coding of occurrence data into user-defined units, such as, countries or native versus invasive ranges, see Töpel et al. (2016). The data gathering and quality control framework outlined here will also be used to select data needed to account for (spatial) biases in occurrence data sets (see below). To refine global model outputs to Belgian-level predictions of invasion potential, the Belgian occurrence records gathered in task 2.2 will be used (Gallien et al. 2012).

\section{Environmental predictor variables}

The global model needs spatial climate data that are available worldwide (i.e. data need to cover all areas where species occurrences are drawn from), and these data will be obtained through recognized online repositories such as WorldClim (Hijmans et al. 2005), CliMond (Kriticos et al. 2011) and CHELSA (Karger et al. 2016). Climatic predictor variables should relate as closely as possible to species ecophysiological requirements (Randin et al. 2006). Selecting tailored species-specific predictor variables is however not practical, nor necessary (Austin and Van Niel 2010, Araújo and Peterson 2012) and therefore, taxa-specific default climatic predictor sets will be selected (e.g for birds see Root (1988), Barbet-Massin et al. (2012a), for amphibians see Vasconcelos et al. (2011), for plants see Petitpierre et al. (2012), for stream macroinvertebrates see Domisch et al. (2013)). Such taxa specific climate prediction selections will be made based on literature and discussions with experts both within and outside the TrIAS consortium. To obtain detailed and robust Belgian-level predictions of species' invasion potential, taxon-specific default predictor sets will be created based on detailed datasets specific to the country. Climate data selection, including the selection of appropriate climate change scenarios, will 
be done in close collaboration with TrIAS consortium partner KMI (see above, task 2.3 for more details on available climate data). Whereas climate is a principal driver of species distributions at large spatial scales, more fine-grained occurrence patterns are determined by available habitat features as well (Pearson and Dawson 2003, Bellard et al. 2013). Therefore, in addition to climate, relevant land-use features (proxies for habitat) will be added to the predictor sets as well. To that end, appropriate data sets will be discussed with the consortium partners but will include detailed GIS datasets held by TrIAS partners such as land cover data, Natura2000 habitats, soil layers and layers indicating sites of high conservation value. Whenever required and possible, the GIS datasets from different regional sources will be standardized to allow for generalization across the Belgian territory.

\section{TASK 4.2 - Risk mapping development}

Model building: spatially explicit predictions of invasion risk will be generated using an ensemble-modelling framework such as biomod2 (Thuiller et al. 2016) or sdm (Naimi and Araújo 2016). A large number of modelling algorithms has been proposed, but no single model optimization technique will prove to be best under all circumstances (Qiao et al. 2015). This is especially true when models are used to project distribution of species into independent situations, which is the case for invasive species and future climate change scenarios (Mainali et al. 2015). Ensemble-models account for such inter-algorithm variability by simulating species occurrences across multiple algorithms, data-input strategies and boundary conditions (see below, Araujo and New 2007). Both global and Belgian-level ensemble models will account for the following factors. (1) Inter-algorithm variability will be mitigated by running up to 15 different modelling algorithms (see Thuiller et al. 2016 and Naimi and Araújo 2016 for details). (2) The data mobilization frameworks described above will results in sets of presence-only occurrence data (i.e. few to no (reliable) species absence data will be available, Lobo et al. (2010)), and model calibration will therefore rely on background ('pseudo-absence') data. Multiple pseudo-absence data selection strategies will be employed, following the recommendations of Barbet-Massin et al. (2012b) concerning the appropriate number of pseudo-absence data and the number of model runs, and VanDerWal et al. (2009)) concerning the areas from which to draw pseudo-absence data. (3) Forecasts of potential distributions for invasive species and under climate change likely require model extrapolation to environments outside the range of conditions on which the models are calibrated (Fitzpatrick and Hargrove 2009). Uncertainty deriving from such extrapolation will be assessed by 'clamping' of response curves to the edge value within the calibration area, truncation or extrapolation of response curves (Phillips et al. 2006, Owens et al. 2013). (4) Presence-only SDMs may be especially sensitive to (spatial) sampling biases (Phillips et al. 2009), and such biases are likely to be present in occurrence data sets gathered from online repositories (Boakes et al. 2010, Meyer et al. 2016). Therefore, following Fourcade et al. (2014), up to five methods for correcting sampling bias will be applied. Note that for one of these methods, the 'bias file method' (Dudík et al. 2005), a grid layer representing sampling effort will be approximated by the aggregation of occurrences from closely related taxa (sensu Phillips et al. 2009). Global ensemble-models will additionally account for uncertainty related to occurrence data 
selection strategies for characterizing species full climatic niche (i.e. use of native-range data only, native-range plus Belgian occurrences, or native-range plus alien occurrences worldwide, sensu Broennimann and Guisan (2008) and Stiels et al. (2014). The integration of the global and Belgian-level models will be achieved by applying global model estimates of invasion potential across Belgium to weight the pseudo-absence data selected for the Belgian-level ensemble models (as per Gallien et al. 2012). When global model projections show a high level of agreement with selected Belgian-level pseudo-absences (i.e. a low invasion potential estimates), a high weight will be attributed to the pseudo-absence (i.e. it probably represents a 'true' absence), and vice versa. Weights will be determined by means of an inverse logistic transformation to obtain stronger discrimination between the predictions of absences and presences (see Gallien et al. (2012) for details). Thus, Belgian-level ensemble models will additionally account for differential pseudo-absence weightings based on global model outputs. All predictions will be generated for current conditions, as well as for climate change scenarios on a 30-year basis, up to the year 2100 .

Model evaluation: Predictive accuracy of models will be evaluated in the following ways. (1) Global model projections derived from native-range data only will be evaluated against invasive range occurrence data. Such invasive range occurrence data represent a truly independent dataset and allow for the strongest evaluation of model performance possible (Araújo and Guisan 2006). (2) Predictions of global native+invasive range models and Belgian-level models will be evaluated using k-fold cross validation techniques (sensu Hijmans 2012). Hereby, (a range of) model evaluation statistics are computed from model predictions for sites of presence and absence that were not used to train (i.e. fit) the model. (3) For all models created, MESS maps (Multivariate Environmental Similarity Surfaces) will be constructed. MESS maps indicate areas where predictor variables occur outside the range of values contained in model training regions, and predictions of invasion risk in these areas should be treated cautiously (Elith et al. 2010).

Model post-processing: The above-mentioned ensemble models will results in a large number of model predictions, allowing to derive, for each location (i.e. grid pixel), a probability distribution of invasion potential rather than a single crude value. This allows for extraction of average predictions, as well as confidence intervals given varying data inputs and modelling strategies. The central tendencies of model predictions for each invasive species will be obtained through (1) only considering those individual models who meet predetermined model evaluation criteria (sensu Thuiller et al. 2016), (2) applying model averaging strategies on the selected models (e.g. taking the (weighted) mean or median probability of selected models, or committee averaging which involves first transforming the continuous predictions of invasion potential into predicted presences and absences, see Thuiller et al. (2016) for details). Final modelling outputs will allow to clearly communicate key results to managers and policy-makers (e.g. through the use of distribution maps showing projected range distribution through time) while at the same time providing experts with the full range of data, results and uncertainties that are needed to critically interpret establishment capacity in the Harmonia+ risk assessments (task 4.4). All modelling routines mentioned above will be coded in $R$ as an $R$ package (including detailed model descriptions, vignettes and help files) so as to make the modelling framework available to 
each user with a basic knowledge of statistical programming. In addition, full model codes will be uploaded on GitHub in order to allow experts to inspect and modify the codes to their needs.

\section{TASK 4.3 - Risk assessment protocol development}

The Harmonia+ framework was developed during the Belspo-funded Alien Alert project (D'hondt et al. 2015), striving for maximal compliance with internationally accepted standards for risk analysis issued by FAO, OiE and WHO (Maijala 2006). It brings together 30 questions that refer to distinct components of invasion. Together, they cover the stages of introduction, establishment, spread, and multiple kinds of impacts, viz. referring to the health of the environment (including wild species), cultivated plants, domesticated animals and man. In a complete assessment, input is provided by choosing among predefined ordinal answers and by supplementing these with textual clarification. Uncertainty is covered by indicating levels of confidence on the answers. By converting answers into scores, which are then condensed into summary statistics, Harmonia+ allows for quantitative output on stage- and domain-specific and general risks. In its original version, the protocol was designed to be applied to any potentially invasive plant or animal species in terrestrial or freshwater habitats. Similarly, the Pandora protocol applies to potentially harmful parasites and pathogens, the results of which may (but not necessarily need to) feed into Harmonia (Roelandt et al. 2017). Adaptation of Harmonia+ to marine species: So far, the protocol was focussing on terrestrial and freshwater species. Consequently, difficulties arise when applying the protocol to marine species (Vansteenbrugge 2015). It is therefore desirable to adapt the protocol to make it applicable for marine AS. The full Harmonia+ protocol provides general guidance on how to answer questions. They are set to minimize ambiguity with regard to the questions and their potential answers, every single question is furthermore provided with ample guidance, including definitions, conceptual underpinnings, cut-off values and specific examples. Therefore the key guidance will be updated by, taking into account the specific marine terminology and habitats, questions rephrased and relevant examples be identified. Integration of risk modelling and mapping into risk assessment: In the current version of the Harmonia+, the questions dealing with establishment capacity assess the likelihood for an organism to overcome survival and reproduction barriers. The assessor is asked to indicate the suitability of the area's climate for survival and reproduction of the organism by considering the climatic similarity between the area and the organism's current range, both native and alien. A single climatic similarity map for Belgium relative to the world is given as guidance using the CRU TS3.20 set as climatic variables and the Mahalanobis distance as a similarity index (Farber and Kadmon 2003). Considering climate change, the user is invited to revisit each of the Harmonia+ modules under the premise of the future climate, with mid-21st century as proposed time horizon. In order to improve the assessment of establishment capacity, the Harmonia+ protocol will be adjusted to integrate the types of output (results and uncertainties) provided by the risk modelling and mapping approach (tasks 4.1-4.2) described above. Technical development will be accordingly performed on the online version of the protocol (ias.biodive rsity.be/harmoniaplus). As such, the users will be able to critically interpret the 
establishment potential using species-specific maps that include different climate change scenarios rather than rough global climatic similarity.

\section{TASK 4.4 - Risk assessments}

Risk assessments will be performed for emerging species identified from the application of indicators and trends (task 3.3) using the updated version of Harmonia+ (task 4.3) and the integrated risk maps as baseline information (task 4.2). Expert elicitation will involve experts from the TrIAS consortium as well as experts selected from the expert registry of the Belgian Forum on Invasive Species (http://ias.biodiversity.be/registry/index) and marine experts from the 'Alien species in the Belgian part of the North Sea and adjacent estuaries' (www.vliz.be/en/imis? module=project\&proid=2170). Facilitation of the process will be done by the BBPF. Particular attention will be paid to transparency and repeatability of assessments and quality control of risk assessments. A consensus building process will be applied to capture opinions of minimum four different experts, thereby maximizing the evidential basis (Mukherjee et al. 2015). Multi-expert risk assessment based on individual assessments with consensus building allows to track different types of uncertainty, reduce subjectivity in the scores and to calculate expert agreement and confidence levels (Vanderhoeven et al. in press). As such, unclear questions, for example due to linguistic uncertainty, can be explained and resolved during the risk assessment process. Lack of evidence can be flagged and contradicting information can easily be tracked and discussed. The different assessments can be treated like survey results and different indices can be used to calculate inter-assessor reliability in addition to overall risk scores (Krippendorff 2012). Importantly, if the predefined level of consensus is not reached, it also identifies the extent of disagreement which is important for decision making. TrlAS will use an online group support system developed by the Belgian Biodiversity Platform to facilitate the consensus building process.

\section{WP5 - Informing policy and stakeholders}

Disseminating the information on the risk of AS is a critical part of the risk analysis process. Effective communication requires the definition of target audience, objectives, clear messages and tools to be used, and evaluation of the outcomes (Brunel 2014). It is therefore important to involve professional communication skills and to take into account existing experiences. TrIAS will benefit from the communication expertise of the Belgian Biodiversity Platform and its community of practice, the Belgian Forum on Invasive Species (BFIS) (Vanderhoeven et al. 2015). The BFIS consists of an interdisciplinary group of about 150 persons (50\% researchers, $20 \%$ policy makers and $30 \%$ stakeholders), allowing for collaborative learning, an efficient knowledge exchange and networking capacity on IAS. A major tool developed through this forum is Harmonia, an information system on AS that will be used as a communication hub for TrIAS to inform policy and stakeholders (http:// ias.biodiversity.be). More research-oriented, conference posters and talks exhibited by the partners will promote the project and its outcomes at appropriate national and international conferences. Attention will be paid to the following considerations: 
- $\quad$ Project website: We will use the Open Science Framework (OSF, https://osf.io/) to host a project website for TrIAS. OSF allows the documentation and communication on the project in a wiki, facilitates collaboration among the partners and external collaborators, integrates with tools such as GitHub, and provides a means to cite an ongoing open science project.

- $\quad$ Access to TrIAS products: Many of the outputs of the project, particularly maps and data layers, have many potential scientific applications in and beyond IAS research. These will be made available and communicated to scientists. Open source code will be deposited publicly on GitHub (https://github.com), an online code collaboration platform.

- $\quad$ Academic publication: For datasets/checklists published through TrIAS, data papers to peer reviewed, open access journals will be considered. Also, significant results, protocols and insights that emerge from the research will also be published in open access journals.

- Internal promotion within the institution: The project will also be promoted internally within our institutions to ensure long-term sustainability of the project. We will support and encourage the submission of additional grant proposals by our scientists who want to use this workflow to generate data for their research projects.

\section{TASK 5.1 - Communication plan}

This task will allow TrIAS to plan and coordinate communication actions. The goal of the plan is to improve the impact and visibility of TrlAS activities, by putting forward a coherent image and by identifying and focalizing on its core target and audience. Following the approach of the Belgian Biodiversity Platform, TrIAS communication will be neutral, scientifically sound, comprehensive and based on factual information. It must provide policy-relevant - but not policy-prescriptive - information; and it should ascertain equitable, unbiased representation of, and networking with and amongst, scientists and policy makers. The communication plan will include an overview of communication actions across the work packages and identify the top level messages of relevance to different target audiences.

\section{TASK 5.2 - Risk communication}

Beyond the classical risk scores allocated to species in the risk assessments, TrlAS will review and further develop innovative graphic tools to facilitate the integration of risk and related uncertainty. As such, the scientific information on Harmonia will be ready for use for policy makers and managers. A particular attention will be paid to explicit communication on the interpretation and use of risk maps and the consideration of the climate change perspective by providing detailed documentation on models and assessments development (Venette et al. 2010). 


\section{TASK 5.3 - Integration of TrIAS output in the national IAS information system Harmonia}

The AS checklist (task 2.1), AS distribution maps (task 2.2) and the outcome of risk evaluations (task 3.3), including risk maps and graphic outputs will be integrated in the national information system Harmonia (http://ias.biodiversity.be). As a result, the main portal will be updated to allow the inclusion of these new types of outputs.

\section{TASK 5.4 - Targeted communication actions}

A particular effort will be done to 1) explain the importance of openly published data to effectively tackle IAS at several levels in the management cycle; 2) Broadcast opportunities for involvement in data publication amongst target groups; 3) Promote findings of the project widely (such as the developed automated procedures and risk evaluation tools), using appropriate mechanisms and in a format tailored to target audiences; 4) Promote project findings strategically. Two milestone communication events are planned throughout the project, geared towards different stakeholder groups and with different objectives. These include:

- A session at an international conference to showcase the results and methodology of TrIAS and gain feedback from an international audience of scientists and experts (end of year 2);

- A symposium aimed at informing the community of practice on IAS in Belgium on the outcomes of the project (year 3).

Targeted communication actions will aim at increasing the participation of the public in IAS recording. A particularly important group to reach out to are naturalist observers such as the user community of 'waarnemingen.be' (Natuurpunt) and 'observations.be' (Natagora), the marine citizen science initiative "SeaWatch-B" (VLIZ, http://www.seawatch-b.be/), or official portals such as the regional institutional portal for biodiversity observations (http:// observatoire.biodiversite.wallonie.be/encodage). We would like to encourage recording activity on AS.

\section{Expected impacts of the research and compliance of the research with the expected impacts}

\section{Expected scientific impacts / research community}

IAS are an international problem and as such require cooperative international action. By basing TrIAS on the tenets of open science and in global repositories we facilitate an international approach and will lead the way in providing scientific basis for decisionmaking in conservation management. Results of our analyses will be published in international open access journals. Also, in the medium term, additional observations from Belgium will help other countries model and assess the risks of these invasive species under different future scenarios. In the long term, the consolidation, standardization and 
openness of data are likely to lead to novel scientific applications of those data and workflows that go beyond what TrlAS is proposing.

\section{Expected impacts on policy support / policy makers}

Much has been written about the importance of evidence-based decision making, however policy makers still find themselves with inadequate, contradictory information. This information can be out of date, not communicated clearly and advice may lack clear expressions of certainty. This is as true for information on IAS as it is for many other policy areas. There are several causes of this, but they include the fragmented ownership of data resources; a lack of information technology infrastructure and the lack standardization. TrIAS will address these issues by creating a rapid, joined-up and sustainable way to inform policy on IAS in Belgium. The time it takes from the observation of an organism in the field, to that observation being used policy will be reduced from years to months.

\section{Expected societal impacts}

TrIAS will address goals 9 and 15 of the sustainable development agenda of the UN. These are specifically to "build a resilient infrastructure and foster innovation", but also to protect biodiversity and sustainable land-use. Controlling and potentially eradicating AS is expensive, however, these costs can be reduced significantly through rapid targeted actions. The dramatic reduction in the time from the collection of observations to the creation of actionable evidence should have a positive impact on the outcomes of management actions, by speeding reaction times and reducing wasted effort. Such outcomes will also have positive benefits for the reduction of animal suffering during management and for the reduction of coincidental damage to ecosystems due to management actions on IAS. An essential element in the whole information flow are the volunteers and professionals who collect and collate observations and checklists in Belgium. This project will valorize their effort to improve knowledge and conserve Belgium's natural heritage. We can expect that TrIAS will encourage their work by showing them how their observations help conserve biodiversity. Furthermore, TrIAS will bring the work of these organizations to the attention of policy makers, making them more aware of the vital role these organizations have in monitoring biodiversity. By doing so, we expect additional societal benefits such as improved science literacy among participants and a greater understanding and awareness of the invasive species issue.

\section{Funding program}

This was a proposal to the Belgian Science Policy Office call for Belgian Research Action through Interdisciplinary Networks (BRAIN). 


\section{References}

- $\quad$ Araujo M, New M (2007) Ensemble forecasting of species distributions. Trends in Ecology \& Evolution 22 (1): 42-47. https://doi.org/10.1016/i.tree.2006.09.010

- $\quad$ Araújo M, Guisan A (2006) Five (or so) challenges for species distribution modelling. Journal of Biogeography 33 (10): 1677-1688. https://doi.org/10.1111/ j.1365-2699.2006.01584.x

- $\quad$ Araújo M, Peterson AT (2012) Uses and misuses of bioclimatic envelope modeling. Ecology 93 (7): 1527-1539. https://doi.org/10.1890/11-1930.1

- $\quad$ Austin M, Van Niel K (2010) Improving species distribution models for climate change studies: variable selection and scale. Journal of Biogeography 38 (1): 1-8. https:// doi.org/10.1111/j.1365-2699.2010.02416.x

- $\quad$ Barbet-Massin M, Thuiller W, Jiguet F (2012a) The fate of European breeding birds under climate, land-use and dispersal scenarios. Global Change Biology 18: 881-890. https://doi.org/10.1111/j.1365-2486.2011.02552.x

- $\quad$ Barbet-Massin M, Jiguet F, Albert CH, Thuiller W (2012b) Selecting pseudo-absences for species distribution models: how, where and how many? Methods in Ecology and Evolution 3 (2): 327-338. https://doi.org/10.1111/j.2041-210x.2011.00172.x

- Beaumont L, Gallagher R, Leishman M, Hughes L, Downey P (2014) How can knowledge of the climate niche inform the weed risk assessment process? A case study of Chrysanthemoides monilifera in Australia. Diversity and Distributions 20 (6): 613-625. https://doi.org/10.1111/ddi.12190

- Beck J, Böller M, Erhardt A, Schwanghart W (2014) Spatial bias in the GBIF database and its effect on modeling species' geographic distributions. Ecological Informatics 19: 10-15. https://doi.org/10.1016/..ecoinf.2013.11.002

- $\quad$ Bellard C, Thuiller W, Leroy B, Genovesi P, Bakkenes M, Courchamp F (2013) Will climate change promote future invasions? Global Change Biology 19: 3740-3748. https://doi.org/10.1111/gcb.12344

- Biała K, Condé S, Delbaere B, Jones-Walters L, Torre-Marín A (2012) Streamlining European biodiversity indicators 2020: Building a future on lessons learnt from the SEBI 2010 process. European Environment Agency, Copenhagen, 45 pp. [ISBN 978-92-9213-326-9] https://doi.org/10.2800/55751

- Boakes E, McGowan PK, Fuller R, Chang-qing D, Clark N, O'Connor K, Mace G (2010) Distorted Views of Biodiversity: Spatial and Temporal Bias in Species Occurrence Data. PLoS Biology 8 (6): e1000385. https://doi.org/10.1371/journal.pbio.1000385

- Boets P, Brosens D, Lock K, Adriaens T, Aelterman B, Mertens J, Goethals P (2016) Alien macroinvertebrates in Flanders (Belgium). Aquatic Invasions 11 (2): 131-144. https://doi.org/10.3391/ai.2016.11.2.03

- Broennimann O, Guisan A (2008) Predicting current and future biological invasions: both native and invaded ranges matter. Biology Letters 4 (5): 585-589. https:// doi.org/10.1098/rsbl.2008.0254

- $\quad$ Broennimann O, Treier UA, Müller-Schärer H, Thuiller W, Peterson AT, Guisan A (2007) Evidence of climatic niche shift during biological invasion. Ecology Letters 10 (8): 701-709. https://doi.org/10.1111/j.1461-0248.2007.01060.x 
- $\quad$ Brunel S (2014) How to communicate on pests and invasive alien plants? Conclusions of the EPPO/CoE/IUCN- ISSG/DGAV/UC/ESAC Workshop. EPPO Bulletin 44 (2): 205-211. https://doi.org/10.1111/epp.12110

- $\quad$ Buisson L, Thuiller W, Casajus N, Lek S, Grenouillet G (2010) Uncertainty in ensemble forecasting of species distribution. Global Change Biology 16 (4): 1145-1157. https:// doi.org/10.1111/j.1365-2486.2009.02000.x

- $\quad$ CBD Secretariat (2010) Strategic Plan for Biodiversity 2011-2020, including Aichi Biodiversity Targets. https://www.cbd.int/sp/targets/. Accessed on: 2017-3-11.

- Chamberlain S, Barve V, Mcglinn D (2016a) Interface to the Global 'Biodiversity' Information Facility 'API'. 0.9.7. CRAN. Release date: 2017-1-21.

- Chamberlain S, Ram K, Hart T (2016b) spocc: Interface to Species Occurrence Data Sources. 0.6.0. CRAN. Release date: 2016-12-07. URL: https://CRAN.R-project.org/ package $=$ spocc

- Demolder H, Peymen J, Adriaens T, Anselin A, Belpaire C, Boone N, Beck LD, Keersmaeker LD, Knijf GD, Devos K, Everaert J, Jansen I, Lommaert L, Maes D, Onkelinx T, Simoens I, Stevens M, Thoonen M, Berge KVD, Aa BVd, Gossum PV, Landuyt WV, Reeth WV, Uytvanck JV, Vermeersch G, Verreycken H (2015) Biodiversity Indicators. State of Nature in Flanders. Mededeling van het Instituut voor Natuur- en Bosonderzoek. Instituut voor Natuur- en Bosonderzoek, Brussels, 56 pp. URL: https:// data.inbo.be/purews/files/11365385/Biodiversitylndicators 2015.pdf

- De Troch R, Hamdi R, Van de Vyver H, Geleyn J, Termonia P (2013) Multiscale Performance of the ALARO-0 Model for Simulating Extreme Summer Precipitation Climatology in Belgium. Journal of Climate 26 (22): 8895-8915. https://doi.org/10.1175/ jcli-d-12-00844.1

- D'hondt B, Vanderhoeven S, Roelandt S, Mayer F, Versteirt V, Ducheyne E, San Martin G, Grégoire J-, Stiers I, Quoilin S, Branquart E (2014) Harmonia+ and Pandora+ : risk screening tools for potentially invasive organisms. Belgian Biodiversity Platform, Brussels 63[In en]. URL: http://ias.biodiversity.be/harmoniaplus

- D'hondt B, Vanderhoeven S, Roelandt S, Mayer F, Versteirt V, Adriaens T, Ducheyne E, Martin GS, Grégoire J, Stiers I, Quoilin S, Cigar J, Heughebaert A, Branquart E (2015) Harmonia + and Pandora +: risk screening tools for potentially invasive plants, animals and their pathogens. Biological Invasions 17 (6): 1869-1883. https://doi.org/10.1007/ s10530-015-0843-1

- Di Febbraro M, Lurz PW, Genovesi P, Maiorano L, Girardello M, Bertolino S (2013) The Use of Climatic Niches in Screening Procedures for Introduced Species to Evaluate Risk of Spread: A Case with the American Eastern Grey Squirrel. PLoS ONE 8 (7): e66559. https://doi.org/10.1371/journal.pone.0066559

- Domisch S, Araújo MB, Bonada N, Pauls SU, Jähnig SC, Haase P (2013) Modelling distribution in European stream macroinvertebrates under future climates. Global Change Biology 19: 752-762. https://doi.org/10.1111/gcb.12107

- $\quad$ Dudík M, Phillips SJ, Schapire RE (2005) Correcting sample selection bias in maximum entropy density estimation. In: Weiss Y, Schölkopf B, Platt J (Eds) Advances in neural information processing systems., 17. Advances in neural information processing systems, Vancouver, 2004. MIT Press, 323-330 pp. [ISBN 9780262195348 ].

- Easterling DR (2000) Climate Extremes: Observations, Modeling, and Impacts. Science 289 (5487): 2068-2074. https://doi.org/10.1126/science.289.5487.2068 
- $\quad$ Elith J, Kearney M, Phillips S (2010) The art of modelling range-shifting species. Methods in Ecology and Evolution 1 (4): 330-342. https://doi.org/10.1111/ j.2041-210x.2010.00036.x

- $\quad$ Ertz D, Diederich P, Brand AM, Boom Pvd, Sérusiau E (2008) New or interesting lichens and lichenicolous fungi from Belgium, Luxembourg and northern France. XI. Bulletin de la Société des naturalistes luxembourgeois 109: 35-51. URL: http://snl.lu/publications/ bulletin/SNL 2008109035 051.pdf

- European Commission (2011) Our life insurance, our natural capital: an EU biodiversity strategy to 2020. European Commission, Brussels, 17 pp. URL: http://eur-lex.europa.eu/ legal-content/EN/TXT/?uri=CELEX:52011DC0244

- $\quad$ European Environment Agency (2012) Streamlining European biodiversity indicators 2020: Building a future on lessons learnt from the SEBI 2010 process. EEA Technical report No 11/2012. European Environment Agency, Copenhagen, 45 pp. [In English]. [ISBN 978-92-9213-326-9] https://doi.org/10.2800/55751

- Farber O, Kadmon R (2003) Assessment of alternative approaches for bioclimatic modeling with special emphasis on the Mahalanobis distance. Ecological Modelling 160: 115-130. https://doi.org/10.1016/s0304-3800(02)00327-7

- $\quad$ Fitzpatrick M, Hargrove W (2009) The projection of species distribution models and the problem of non-analog climate. Biodiversity and Conservation 18 (8): 2255-2261. https://doi.org/10.1007/s10531-009-9584-8

- $\quad$ Fourcade Y, Engler JO, Rödder D, Secondi J (2014) Mapping Species Distributions with MAXENT Using a Geographically Biased Sample of Presence Data: A Performance Assessment of Methods for Correcting Sampling Bias. PLOS ONE 9 (5): 97122 . https:// doi.org/10.1371/journal.pone.0097122

- $\quad$ Franklin J (2010) Moving beyond static species distribution models in support of conservation biogeography. Diversity and Distributions 16 (3): 321-330. https:// doi.org/10.1111/j.1472-4642.2010.00641.x

- $\quad$ Gallardo B, Zieritz A, Aldridge DC (2013) Targeting and Prioritisation for INS in the RINSE Project Area. University ofCambridge, Cambridge, UK, 98 pp. [In English]. URL: http://www.rinse-europe.eu/assets/_files/rinse-wp1-report-en-.pdf

- Gallardo B, Zieritz A, Adriaens T, Bellard C, Boets P, Britton JR, Newman J, van Valkenburg JCH, Aldridge $D$ (2015) Trans-national horizon scanning for invasive nonnative species: a case study in western Europe. Biological Invasions 18 (1): 17-30. https://doi.org/10.1007/s10530-015-0986-0

- Gallien L, Douzet R, Pratte S, Zimmermann N, Thuiller W (2012) Invasive species distribution models - how violating the equilibrium assumption can create new insights. Global Ecology and Biogeography 21 (11): 1126-1136. https://doi.org/10.1111/ j.1466-8238.2012.00768.x

- $\quad$ Gaston K (1991) How Large Is a Species' Geographic Range? Oikos 61 (3): 434. https://doi.org/10.2307/3545251

- $\quad$ GBIF (2010) GBIF GNA Profile Reference Guide for Darwin Core Archives, version 1.2, released on 15 March 2012 (contributed by Remsen D.P., Döring, M, Robertson, T.). Global Biodiversity Information Facility, Copenhagen, 28 pp. [In English]. URL: http:// links.gbif.org/gbif gna profile reference guide [ISBN 87-92020-25-9]

- GBIF Secretariat (2016) GBIF Backbone Taxonomy. GBIF Secretariat. Release date: 2016-7-25. URL: http://doi.org/10.15468/39omei 
- $\quad$ Giot O, Termonia P, Degrauwe D, Troch RD, Caluwaerts S, Smet G, Berckmans J, Deckmyn A, Cruz LD, Meutter PD, Duerinckx A, Gerard L, Hamdi R, den Bergh JV, Ginderachter MV, Schaeybroeck BV (2016) Validation of the ALARO-0 model within the EURO-CORDEX framework. Geoscientific Model Development 9 (3): 1143-1152. https://doi.org/10.5194/gmd-9-1143-2016

- $\quad$ Groom Q, Desmet P, Vanderhoeven S, Adriaens T (2015) The importance of open data for invasive alien species research, policy and management. Management of Biological Invasions 6 (2): 119-125. https://doi.org/10.3391/mbi.2015.6.2.02

- Guisan A, Zimmermann N (2000) Predictive habitat distribution models in ecology. Ecological Modelling 135: 147-186. https://doi.org/10.1016/s0304-3800(00)00354-9

- Hattingh J (2011) Conceptual clarity, scientific rigour and 'The Stories We Are': engaging with two challenges to the objectivity of invasion biology. In: Richardson D (Ed.) Fifty Years of Invasion Ecology: The Legacy of Charles Elton. John Wiley \& Sons, 432 pp. [ISBN 1444335855].

- Hijmans R (2012) Cross-validation of species distribution models: removing spatial sorting bias and calibration with a null model. Ecology 93 (3): 679-688. https:// doi.org/10.1890/11-0826.1

- Hijmans R, Cameron S, Parra J, Jones P, Jarvis A (2005) Very high resolution interpolated climate surfaces for global land areas. International Journal of Climatology 25 (15): 1965-1978. https://doi.org/10.1002/joc.1276

- Holt J, Leach AW, Knight JD, Griessinger D, MacLeod A, der Gaag DJv, Schrader G, Mumford JD (2012) Tools for visualizing and integrating pest risk assessment ratings and uncertainties*. EPPO Bulletin 42 (1): 35-41. https://doi.org/10.1111/

j.1365-2338.2012.02548.x

- Karger DN, Conrad O, Böhner J, Kawohl T, Kreft H, Soria-Auza RW, Zimmermann N, Linder HP, Kessler M (2016) Climatologies at high resolution for the earth's land surface areas. 2. arxiv.org. Release date: 2016-9-21. URL: https://arxiv.org/abs/1607.00217v2

- Katsanevakis S, Deriu I, D’Amico F, Nunes AL, Sanchez SP, Crocetta F, Arianoutsou M, Bazos I, Christopoulou A, Curto G, Delipetrou P, Kokkoris Y, Panov V, Rabitsch W, Roques A, Scalera R, Shirley SM, Tricarico E, Vannini A, Zenetos A, Zervou S, Zikos A, Cardoso AC (2015) Zeneto,s A, Zervou S European Alien Species Information Network (EASIN): supporting European policies and scientific research. Management of Biological Invasions. 6, 2. 147-157 pp. https://doi.org/10.3391/mbi.2015.6.2.05

- Kotlarski S, Keuler K, Christensen OB, Colette A, Déqué M, Gobiet A, Goergen K, Jacob D, Lüthi D, Meijgaard Ev, Nikulin G, Schär C, Teichmann C, Vautard R, WarrachSagi K, Wulfmeyer V (2014) Regional climate modeling on European scales: a joint standard evaluation of the EURO-CORDEX RCM ensemble. Geoscientific Model Development 7 (4): 1297-1333. https://doi.org/10.5194/gmd-7-1297-2014

- Krippendorff K (2012) Content analysis: An introduction to its methodology. 3. Sage, 441 pp. [ISBN 9781412983150$]$

- $\quad$ Kriticos D, Webber B, Leriche A, Ota N, Macadam I, Bathols J, Scott J (2011) CliMond: global high-resolution historical and future scenario climate surfaces for bioclimatic modelling. Methods in Ecology and Evolution 3 (1): 53-64. https://doi.org/10.1111/ j.2041-210x.2011.00134.x

- Latombe G, Pyšek P, Jeschke J, Blackburn T, Bacher S, Capinha C, Costello M, Fernández M, Gregory R, Hobern D, Hui C, Jetz W, Kumschick S, McGrannachan C, Pergl J, Roy H, Scalera R, Squires Z, Wilson JU, Winter M, Genovesi P, McGeoch M 
(2016) A vision for global monitoring of biological invasions. Biological Conservation https://doi.org/10.1016/j.biocon.2016.06.013

- Layke C, Mapendembe A, Brown C, Walpole M, Winn J (2012) Indicators from the global and sub-global Millennium Ecosystem Assessments: An analysis and next steps. Ecological Indicators 17: 77-87. https://doi.org/10.1016/j.ecolind.2011.04.025

- Lobo J, Jiménez-Valverde A, Hortal J (2010) The uncertain nature of absences and their importance in species distribution modelling. Ecography 33 (1): 103-114. https:// doi.org/10.1111/j.1600-0587.2009.06039.x

- Lodge D, Williams S, Maclsaac H, Hayes K, Leung B, Reichard S, Mack R, Moyle P, Smith M, Andow D, Carlton J, McMichael A (2006) BIOLOGICAL INVASIONS: RECOMMENDATIONS FOR U.S. POLICY AND MANAGEMENT. Ecological Applications 16 (6): 2035-2054. https://doi.org/10.1890/1051-0761(2006)016 [2035:birfup]2.0.co;2

- Maijala R (2006) Risk assessment as a tool for evaluating risk management options for food safety. In: Smulders FM, Collins JD (Eds) Towards a risk-based chain control. 4. Wageningen Academic Publishers, Wageningen, 408 pp. [ISBN 978-90-76998-97-8]. https://doi.org/10.3920/978-90-8686-583-3

- Mainali K, Warren D, Dhileepan K, McConnachie A, Strathie L, Hassan G, Karki D, Shrestha B, Parmesan C (2015) Projecting future expansion of invasive species: comparing and improving methodologies for species distribution modeling. Global Change Biology 21 (12): 4464-4480. https://doi.org/10.1111/gcb.13038

- McGeoch M, Latombe G (2015) Characterizing common and range expanding species. Journal of Biogeography 43 (2): 217-228. https://doi.org/10.1111/jbi.12642

- McGeoch M, Spear D, Kleynhans E, Marais E (2012) Uncertainty in invasive alien species listing. Ecological Applications 22 (3): 959-971. https:// doi.org/10.1890/11-1252.1

- $\quad$ McGeoch MA, Squires ZE (2015) An Essential Biodiversity Variable approach to monitoring biological invasions: Guide for Countries. 2. GEO BON Technical Series, 13 pp. URL: http://www.geobon.org/Downloads/reports/GEOBON/2015/ MonitoringBiologicallnvasions.pdf

- McLure M, Level A, Cranston C, Oehlerts B, Culbertson M (2014) Data Curation: A Study of Researcher Practices and Needs. portal: Libraries and the Academy 14 (2): 139-164. https://doi.org/10.1353/pla.2014.0009

- Meyer C, Weigelt P, Kreft H (2016) Multidimensional biases, gaps and uncertainties in global plant occurrence information. Ecology Letters 19 (8): 992-1006. https:// doi.org/10.1111/ele.12624

- Mukherjee N, Hugé J, Sutherland W, McNeill J, Opstal MV, Dahdouh-Guebas F, Koedam N (2015) The Delphi technique in ecology and biological conservation: applications and guidelines. Methods in Ecology and Evolution 6 (9): 1097-1109. https:// doi.org/10.1111/2041-210x.12387

- $\quad$ Naimi B, Araújo M (2016) sdm: a reproducible and extensible R platform for species distribution modelling. Ecography 39 (4): 368-375. https://doi.org/10.1111/ecog.01881

- $\quad$ Owens H, Campbell L, Dornak LL, Saupe E, Barve N, Soberón J, Ingenloff K, LiraNoriega A, Hensz C, Myers C, Peterson AT (2013) Constraints on interpretation of ecological niche models by limited environmental ranges on calibration areas. Ecological Modelling 263: 10-18. https://doi.org/10.1016/i.ecolmodel.2013.04.011 
- $\quad$ Pagad S, Hayes K, Katsanevakis S, Costello MJ (2016) World Register of Introduced Marine Species (WRIMS). http://www.marinespecies.org/introduced. Accessed on: 2016-8-26.

- Pearson R, Dawson T (2003) Predicting the impacts of climate change on the distribution of species: are bioclimate envelope models useful? Global Ecology and Biogeography 12: 361-371. https://doi.org/10.1046/j.1466-822X.2003.00042.x

- Pereira HM, Ferrier S, Walters M, Geller GN, Jongman RHG, Scholes RJ, Bruford MW, Brummitt N, Butchart SHM, Cardoso AC, Coops NC, Dulloo E, Faith DP, Freyhof J, Gregory RD, Heip C, Hoft R, Hurtt G, Jetz W, Karp DS, McGeoch MA, Obura D, Onoda Y, Pettorelli N, Reyers B, Sayre R, Scharlemann JPW, Stuart SN, Turak E, Walpole M, Wegmann M (2013) Essential Biodiversity Variables. Science 339 (6117): 277-278. https://doi.org/10.1126/science.1229931

- $\quad$ Petitpierre B, Kueffer C, Broennimann O, Randin C, Daehler C, Guisan A (2012) Climatic Niche Shifts Are Rare Among Terrestrial Plant Invaders. Science 335 (6074): 1344-1348. https://doi.org/10.1126/science.1215933

- $\quad$ Phillips S, Anderson R, Schapire R (2006) Maximum entropy modeling of species geographic distributions. Ecological Modelling 190: 231-259. https://doi.org/10.1016/ j.ecolmodel.2005.03.026

- $\quad$ Phillips S, Dudík M, Elith J, Graham C, Lehmann A, Leathwick J, Ferrier S (2009) Sample selection bias and presence-only distribution models: implications for background and pseudo-absence data. Ecological Applications 19 (1): 181-197. https:// doi.org/10.1890/07-2153.1

- Prein AF, Gobiet A, Truhetz H, Keuler K, Goergen K, Teichmann C, Maule CF, Meijgaard Ev, Déqué M, Nikulin G, Vautard R, Colette A, Kjellström E, Jacob D (2015) Precipitation in the EURO-CORDEX $0.11^{\circ}$ and $0.44^{\circ}$ simulations: high resolution, high benefits? Climate Dynamics 46: 383-412. https://doi.org/10.1007/s00382-015-2589-y

- Qiao H, Soberón J, Peterson AT (2015) No silver bullets in correlative ecological niche modelling: insights from testing among many potential algorithms for niche estimation. Methods in Ecology and Evolution 6 (10): 1126-1136. https:// doi.org/10.1111/2041-210x.12397

- $\quad$ Rabitsch W, EssI F, Genovesi P, Scalera R (2012) Invasive alien species indicators in Europe - A review of streamlining European biodiversity (SEBI) Indicator 10. European Environment Agency, Copenhagen, 44 pp. [In English]. [ISBN 978-92-9213-342-9] https://doi.org/10.2800/64181

- $\quad$ Rabitsch W, Genovesi P, Scalera R, Biała K, Josefsson M, EssI F (2016) Developing and testing alien species indicators for Europe. Journal for Nature Conservation 29: 89-96. https://doi.org/10.1016/i.jnc.2015.12.001

- Randin C, Dirnböck T, Dullinger S, Zimmermann N, Zappa M, Guisan A (2006) Are niche-based species distribution models transferable in space? Journal of Biogeography 33 (10): 1689-1703. https://doi.org/10.1111/j.1365-2699.2006.01466.x

- Robertson T, Döring M, Guralnick R, Bloom D, Wieczorek J, Braak K, Otegui J, Russell L, Desmet P (2014) The GBIF Integrated Publishing Toolkit: Facilitating the Efficient Publishing of Biodiversity Data on the Internet. PLoS ONE 9 (8): e102623. https:// doi.org/10.1371/journal.pone.0102623

- Roelandt S, Stede Y, D'hondt B, Koenen F (2017) The Assessment of African Swine Fever Virus Risk to Belgium Early 2014, using the Quick and Semiquantitative Pandora 
Screening Protocol. Transboundary and Emerging Diseases 64: 237-249. https:// doi.org/10.1111/tbed.12365

- Root T (1988) Environmental Factors Associated with Avian Distributional Boundaries. Journal of Biogeography 15 (3): 489-505. https://doi.org/10.2307/2845278

- Roy H, Preston C, Harrower C, Rorke S, Noble D, Sewell J, Walker K, Marchant J, Seeley B, Bishop J, Jukes A, Musgrove A, Pearman D, Booy O (2014) GB Non-native Species Information Portal: documenting the arrival of non-native species in Britain. Biological Invasions 16 (12): 2495-2505. https://doi.org/10.1007/s10530-014-0687-0

- Sotiaux A, Vanderpoorten A (2001) Checklist of the Bryophytes of Belgium. Journal of Botany 134: 97-120. URL: http://www.jstor.org/stable/20794485

- Stiels D, Gaißer B, Schidelko K, Engler J, Rödder D (2014) Niche shift in four nonnative estrildid finches and implications for species distribution models. Ibis 157 (1): 75-90. https://doi.org/10.1111/ibi.12194

- Thuiller W, Georges D, Engler R, Breiner F (2016) biomod2: Ensemble Platform for Species Distribution. 3.3-7. CRAN. Release date: 2016-3-01. URL: ftp:// ftp2.de.freebsd.org/pub/misc/cran/web/packages/biomod2/biomod2.pdf

- Tittensor DP, Walpole M, Hill SLL, Boyce DG, Britten GL, Burgess ND, Butchart SHM, Leadley PW, Regan EC, Alkemade R, Baumung R, Bellard C, Bouwman L, BowlesNewark NJ, Chenery AM, Cheung WWL, Christensen V, Cooper HD, Crowther AR, Dixon MJR, Galli A, Gaveau V, Gregory RD, Gutierrez NL, Hirsch TL, Hoft R, Januchowski-Hartley SR, Karmann M, Krug CB, Leverington FJ, Loh J, Lojenga RK, Malsch K, Marques A, Morgan DHW, Mumby PJ, Newbold T, Noonan-Mooney K, Pagad SN, Parks BC, Pereira HM, Robertson T, Rondinini C, Santini L, Scharlemann JPW, Schindler S, Sumaila UR, Teh LSL, Kolck Jv, Visconti P, Ye Y (2014) A mid-term analysis of progress toward international biodiversity targets. Science 346 (6206): 241-244. https://doi.org/10.1126/science.1257484

- Töpel M, Zizka A, Calió MF, Scharn R, Silvestro D, Antonelli A (2016) SpeciesGeoCoder: Fast Categorization of Species Occurrences for Analyses of Biodiversity, Biogeography, Ecology, and Evolution. Systematic Biology syw064. https:// doi.org/10.1093/sysbio/syw064

- Václavík T, Meentemeyer R (2011) Equilibrium or not? Modelling potential distribution of invasive species in different stages of invasion. Diversity and Distributions 18 (1): 73-83. https://doi.org/10.1111/j.1472-4642.2011.00854.x

- Vandepitte L, De Pooter D, Lescrauwaet A, Fockedey N, Jan M (Eds) (2012) Nietinheemse soorten van het Belgische deel van de Noordzee en aanpalende estuaria. VLIZ Species Publication, 59. Vlaams Instituut vorr de Zee, OOstende, 372 pp. [In Dutch].

- Vanderhoeven S, Adriaens T, D'hondt B, Gossum HV, Vandegehuchte M, Verreycken H, Cigar J, Branquart E (2015) A science-based approach to tackle invasive alien species in Belgium - the role of the ISEIA protocol and the Harmonia information system as decision support tools. Management of Biological Invasions 6 (2): 197-208. https:// doi.org/10.3391/mbi.2015.6.2.10

- Vanderhoeven S, Branquart E, Casaer J, D'hondt B, Hulme PE, Shwartz A, Strubbe D, Turbe A, Verreycken $\mathrm{H}$, Adriaens $\mathrm{T}$ (in press) Beyond protocols: improving the reliability of expert-based risk analysis underpinning invasive species policies. Biological Invasions. 
- VanDerWal J, Shoo L, Graham C, Williams S (2009) Selecting pseudo-absence data for presence-only distribution modeling: How far should you stray from what you know? Ecological Modelling 220 (4): 589-594. https://doi.org/10.1016/j.ecolmodel.2008.11.010

- Vanderweyen A, Fraiture A (2007) Catalogue des Uredinales de Belgique, 1re partie, Chaconiaceae, Coleosporiaceae, Cronartiaceae, Melampsoraceae, Phragmidiaceae, Pucciniastraceae, Raveneliaceae et Uropyxidaceae. Lejeunia, Revue de Botanique 183.

- Vanderweyen A, Fraiture A (2014) CATALOGUE DES USTILAGINALES S.L. DE Belgique. Lejeunia, Revue de Botanique 193 URL: http://popups.ulg.ac.be/0457-4184/ index.php?id=1150

- $\quad$ van Kleunen M, Dawson W, Essl F, Pergl J, Winter M, Weber E, Kreft H, Weigelt P, Kartesz J, Nishino M, Antonova L, Barcelona J, Cabezas F, Cárdenas D, Cárdenas-Toro J, Castaño N, Chacón E, Chatelain C, Ebel A, Figueiredo E, Fuentes N, Groom Q, Henderson L, Inderjit, Kupriyanov A, Masciadri S, Meerman J, Morozova O, Moser D, Nickrent D, Patzelt A, Pelser P, Baptiste M, Poopath M, Schulze M, Seebens H, Shu W, Thomas J, Velayos M, Wieringa J, Pyšek P (2015) Global exchange and accumulation of non-native plants. Nature 525 (7567): 100-103. https://doi.org/10.1038/nature14910 van Oldenborgh GJ, Doblas Reyes FJ, Drijfhout SS, Hawkins E (2013) Reliability of regional climate model trends. Environmental Research Letters 8 (1): 014055. https:// doi.org/10.1088/1748-9326/8/1/014055

- Vansteenbrugge L (2015) The non-indigenous ctenophore Mnemiopsis leidyi in the southern North Sea: Ecological and socio-economic effects related to its trophic position and the current distribution of gelatinous zooplankton. Institute for Agricultural and Fisheries Research (ILVO), Ghent, 287 pp. URL: http://pure.ilvo.vlaanderen.be/portal/ files/3783423/Reviewed PhD thesis Lies Vansteenbrugge.pdf [ISBN 978-90-5989-837-0].

- Vasconcelos T, Rodríguez MÁ, Hawkins B (2011) Species distribution modelling as a macroecological tool: a case study using New World amphibians. Ecography 35 (6): 539-548. https://doi.org/10.1111/j.1600-0587.2011.07050.x

- Venette R, Kriticos D, Magarey R, Koch F, Baker RA, Worner S, Gómez Raboteaux N, McKenney D, Dobesberger E, Yemshanov D, De Barro P, Hutchison W, Fowler G, Kalaris T, Pedlar J (2010) Pest Risk Maps for Invasive Alien Species: A Roadmap for Improvement. BioScience 60 (5): 349-362. https://doi.org/10.1525/bio.2010.60.5.5

- Venette S (2015) Assessing the quality of pest risk models. In: Venette RC (Ed.) Pest Risk Modelling and Mapping for Invasive Alien Species. 7. CAB books, 268 pp. [ISBN 9781780643946].

- Verloove F (2006) Catalogue of neophytes in Belgium (1800-2005). Scripta Botanica Belgica. 39. National Botanic Garden, Meise, Belgium, 89 pp. [In English]. URL: http:// alienplantsbelgium.be/sites/alienplantsbelgium.be/files/tabel 2.pdf [ISBN

90-72619-71-4].

- Verloove F (2016) The Manual of the Alien Plants of Belgium. http:// alienplantsbelgium.be. Accessed on: 2017-2-22.

- Verreycken H, Anseeuw D, Thuyne GV, Quataert P, Belpaire C (2007) The nonindigenous freshwater fishes of Flanders (Belgium): review, status and trends over the last decade. Journal of Fish Biology 71: 160-172. https://doi.org/10.1111/ j.1095-8649.2007.01679.x 
Zieritz A, Armas B, Aldridge D (2014) Registry of non-native species in the Two Seas region countries (Great Britain, France, Belgium and the Netherlands). NeoBiota 23:

65-80. https://doi.org/10.3897/neobiota.23.5665 